\title{
The Empire Has No Clothes
}

Olúfémi O. Táíwò

Georgetown University

\begin{abstract}
Jason Stanley's How Propaganda Works roots the danger of undermining propaganda in an ideology based account of politics, treating individuals' beliefs and social belief systems as the primary target and mechanism of undermining propaganda. In this paper I suggest a theoretical alternative to the role ideology plays in Stanley's theory and theories like it, which I call practice first. A practice first account instead treats public behavior as the primary target of propaganda, and analyzes undermining propaganda as altering the incentive structure that sets the terms for public behavior.
\end{abstract}

\section{Keywords}

Ideology, propaganda, practice first, common ground, incentive structure.

\section{Part I}

Hans Christian Andersen's version of the fable of the Emperor with no clothes goes something like this: the emperor's weavers got gutsy one day, and handed their emperor an empty hangar, claiming that it held a garment made of a mystical fabric which would appear invisible to anyone incompetent or exceptionally stupid. The emperor puts on the fictional garment, which is to say that he walked around naked in full view of his subjects. None of his subjects could bring themselves to point out the obvious - not even the nobleman assigned to hold the 'train' of his nonexistent garment, not even when the emperor is escorted through the town in a celebratory parade. Finally, a young child yelled: "But he hasn't got anything on!" The spell was broken, and the whole town finally acknowledged the emperor's nakedness.

Now, maybe we're supposed to think that the child's cry allowed some people to realize they had been too gullible in seeing the 
emperor's robe and that they should trust their senses. ${ }^{1}$ But I prefer to think of it this way: some, maybe even most of the townspeople already knew for themselves that the emperor was naked. But they weren't willing to act on that knowledge. They accepted something that operated like a belief that the emperor was clothed as a premise in deciding how to act. This belief-like premise ruled out a host of practical options that would otherwise follow from their perception of his nakedness, ranging from comments on the emperor's nakedness to staring, pointing, and laughing. It ruled in practical options likewise in tension with their private descriptions of the world: looking away, nodding in assent to compliments of the emperor's "clothes", even making compliments about the features of the imaginary garments. The child deviated from the resulting social pattern of performing a kind of deference to the emperor which involved accepting the 'fact' that the emperor was clothed as a practical premise, by performing an act that clearly did not accept this premise. The other townsfolk followed her lead.

The moral of the story, for those of us theorizing about ideology and propaganda, is to take stock of exactly how far people's public actions can deviate from their private beliefs when social power is involved. When we've done so, I will argue, we will be in a position to reconsider some uses of ideology as a theoretical device in social philosophy and to develop alternatives.

My first goal for this paper is to argue for what I call a practice first view of the role of mental representations in the explanation of social and political realities. On a practice first view we are only secondarily concerned with the content of individuals' beliefs, dispositions, affects, or other aspects of their psychology when we want to explain what effects social phenomena like propaganda will have on society. We are primarily interested in how individuals' beliefs, dispositions, emotions, and other aspects of their inner psychological lives affect their behavior in a social context, whatever their content. I contrast practice first with ideology and try to motivate the use of practice first views over ideology views. This is the kind of account given by Fields and Fields in Racecraft, Lynne Tirrell in "Genocidal Language Games", and Sally Haslanger in "Racism, Ideology, and

${ }^{1}$ Andersen, The Complete Fairy Tales and Stories. 
Social Movements". ${ }^{2}$

"Ideology" has been notoriously tough to pin down given the myriad literatures that use the term. Tommie Shelby gives a broad characterization of as many as 11 different conceptions of ideology. But Shelby claims that the central role of individuals' beliefs in the explanation of social and political phenomena is a common thread running through these otherwise heterogeneous accounts. ${ }^{3}$ Beliefs, he continues, are "mental representations within the consciousness of individual social actors," whose content concerns "knowledge claims about the way the world is or what has value". ${ }^{4}$ Theorists of ideology concern themselves with "belief systems", where the "ideological beliefs" of the people in the society in question are the basic elements of these systems. When institutions, practices, and speech acts are considered as ideological structures or forces are considered as such derivatively, in terms of how they represent, reinforce, or support ideological belief systems. ${ }^{5}$ In the remainder of the paper I will assume Shelby's characterization of this defining commitment of ideology theories and contrast my preferred practice first alternative with his characterization. ${ }^{6}$

A practice first view contrasts with ideology in three ways. First: both practice first and ideology views take there to be some kind of system of mental representations that is causally related to social and material life. However, a practice first view treats the public mental

\footnotetext{
${ }^{2}$ Fields and Fields (2012) use the term "ideology", but I think the substance of their conception of ideology lines up more with the practice first view than with Shelby's rough characterization of ideology. See Fields and Fields 2012: chapter 4, Tirrell 2012: 187-8, and Haslanger 2017: 7-16.

${ }^{3}$ Shelby 2003.

${ }^{4}$ Shelby 2003: 157 .

${ }^{5}$ Shelby 2003: 157 .

${ }^{6}$ Shelby's broad characterization should not be taken to be categorical or definitional of ideology. Barbara and Karen Fields provide an important example of a conception of ideology that nevertheless gives relationships between mental representations and fields of practical activity center stage. I won't attempt to differentiate practice first from this kind of ideology in this paper, but it is enough for my purposes that there are accounts oriented around individuals' beliefs in the way Shelby describes. See especially Fields and Fields 2012: 134-6, in chapter 4.
} 
representations that make up the content of the common ground as the facts that primarily explain social and political states of affairs. Ideology theory instead treats the beliefs held by individuals as the primary facts that explain social and political states of affairs. Second, a practice first view identifies the public mental representations in the common ground as the paradigm target of political intervention on mental representations in a society. Ideology views the beliefs (and belief-making processes) of individuals as the primary target for interventions. Third, practice first theories grant explanatory relevance to the mental representations they consider in practical, behavioral terms. These mental representations are thought of as practical commitments: commitments to behave and evaluate behavior in certain ways in a social world. They also help establish which representations of which elements of that context are salient for those determinations. Ideology-based theories grant explanatory relevance to the mental representations they consider in terms of their content as descriptions of the world as it is and ought to be.

I argue that a practice first view provides a better explanation of what Jason Stanley terms "undermining propaganda." This test drive is supposed to motivate the further conclusion that a practice first view is not only better on the merits than an ideology view, but that practice first will better serve us in characterizing phenomena already under discussion in the literature on social and political philosophy.

In How Propaganda Works, Jason Stanley takes a conception of ideology on board instead of a practice first view, along with ideology's attendant reliance on claims about the content of beliefs of individual social actors. How Propaganda Works describes contributions to public discourse that tend to erode the very ideals they present, which he terms "undermining propaganda." Stanley argues that undermining propaganda undermines by empowering and sustaining pernicious ideologies. Accordingly, he articulates the danger undermining propaganda poses for the democratic functioning of society in terms of the effects it will have on the beliefs of those affected by the propaganda, which he can assume will causally relate to the future functioning of society from whatever safety the background theory of ideology buys. ${ }^{7}$

\footnotetext{
${ }^{7}$ Stanley dedicates three full chapters to discussion of ideology, considering
} 
In what follows, I attempt to motivate the conclusion that a practice first theoretical orientation is better for independent reasons and also that it gives a better explanation of undermining propaganda than its ideology-based counterpart. In Part II, I draw from philosophy to outline a practice first view of how public mental representations relate to action in a social context (2.1.) and consider how the progression of a conversation can be understood in practical terms (2.2.). Then I use that view to criticize Stanley's characterization of undermining propaganda (2.3.) and briefly gesture at what else a practice first view might get us (2.4.). In Part III, I conclude.

\section{Part II}

\subsection{Common ground and public practical premises}

Common ground, as defined by Robert Stalnaker, refers to the set of propositions that will be treated as mutual knowledge in conversation. ${ }^{8}$ This set of propositions helps shape how the common ground responds to the new information. The common ground is an interpretive resource for individuals, allowing them to coordinate their actions with others' and giving them a basis for interpreting and predicting others' actions.

Individuals affect institutions and communities through their actions, both communicative acts (e.g. gesturing, frowning, and speaking) and other kinds (e.g. voting, buying and selling, producing, caretaking). These actions take place in a social context: the context is made social both by the fact that individuals cohabit the material world in which our actions take place but also by the store of background information that we use to interpret and respond to the things we perceive in the material world together.

ideology as both a structural enabler of propagandistic speech acts and responsive to them. For example, Stanley characterizes the two success conditions for undermining propaganda as entirely in terms of individuals' beliefs: first "people having beliefs that are resistant to the available evidence" and "that the beliefs that are resistant to evidence must themselves be flawed in some way. Stanley 2015: 178.

${ }^{8}$ Stalnaker 2002. 
Common ground consists of the propositions that will be treated as true for the purposes of organizing behavior. I characterize the content of the common ground as public practical premises rather than Stalnaker's term "common belief". This is to emphasize both the relevance of these premises for actions that aren't communicative acts and to gesture at the wide range of reasons to adopt them, including but importantly not limited to buying into the descriptive or normative claims they involve. This draws out an implication of Stalnaker's own characterization of the common ground's content: he explains that the common ground consists of that public information which is accepted as such by those in the conversation. ${ }^{9}$

Acceptance of proffered information is a social behavior. That behavior can be signaled by non-verbal (e.g. nods, patiently listening) or verbal assent, simply subsequent use of information earlier asserted. Similarly, refusal to accept propositions into the common ground can be likewise signaled by nonverbal (shaken heads, rolled eyes) or verbal dissent ("that's preposterous!" "I disagree”), or simply by the perceptible use of the proffered information as a practical premise (e.g. moving your car when someone asserts that you are parked in "their spot").

Acceptance behavior is subject to the same social pressures and incentives as other kinds of behavior in a social context. As such, Stalnaker points out that an audience's acceptance of a proposition as public information is "to treat it as true for some reason" (emphasis added). One may simply be avoiding the costs of challenging the common ground, as one might do when defying common wisdom would threaten one's safety, social status, or welfare. Stalnaker's examples are politically innocuous: "to idealize in an inquiry", "to make assumptions for can be done for reasons other than belief". While we're at it, we could add equally socially weighty but less obviously political reasons for acceptance behavior: fear of embarrassment or ridicule, wanting to avoid rocking the boat to make friends. But the lesson of the naked emperor is that there are politically salient reasons acceptance behavior may be denied or distorted: wanting to ingratiate one's self to a social superior, or wanting to avoid 
coercive violence. ${ }^{10}$ Ideology based views that explain what people do by appeal to what those actions indicate that they believe risk systematically distorting the populations they purport to describe. Robin D.G. Kelley levels exactly this accusation at historians who described Blacks in the United States as acquiescing to their social condition, and James Scott considers different ways of characterizing acceptance behaviors among various oppressed groups. ${ }^{11}$

The kind of coordination involved in the actions facilitated by the common ground result doesn't require most, many, or even any individual person to believe or otherwise relate first personally to the mental representation that is nonetheless used to enable and evaluate behavior. ${ }^{12}$ The outcome of an individual's use of the "common" information in the common ground relates not only to their individual intentions and commitments, then, but also importantly to the broader social practices that form the interpretive context for their actions. Referring to the content of the common ground as public practical premises, both emphasizes the generality of the connection between background information and acting in a social context, and eases exposition of cases where individuals treat information as "common belief" that they do not themselves believe — cases which are of critical importance to debates about propaganda and ideology.

Stanley's foundation in ideology leads him to focus on individuals' beliefs as the mental representations directly threatened by undermining propaganda. As a result, How Propaganda Works focuses on the common ground's propositional content to explain how propaganda works. Stanley appeals to a distinction in two different ways the informational content of the common ground can be updated by communicative acts. A communicative act can add either at-issue or not-at-issue content to the common ground. ${ }^{13}$ At-issue content is

${ }^{10}$ Bright and I term the ability to elicit acceptance behavior "discourse power", and discuss these implications in an unpublished manuscript. Bright and Táíwò 2017.

${ }^{11}$ Kelley 1993, Scott 1990.

${ }^{12}$ Keynes 1936. See Keynes' discussion of a related phenomenon in chapter 12 , section V, now referred to as the "Keynesian beauty contest".

${ }^{13}$ Potts 2013. Christopher Potts develops this distinction in "Presupposition and Implicature", crediting the terminology to William Ladusaw. Also, I say "communicative act" as opposed to "utterance" or "speech act" to include instanc- 
the subject of what is communicated and is generally treated as that which is up for potential challenge by other conversational participants. Not-at-issue content is other content that is added by way of what was said, but is not taken to be at-issue and is generally socially shielded from direct challenged. It is then, in typical cases, directly added to the common ground, without being up for review and potential dismissal by the other participants of the conversation. For example, if I said "Last summer, at her grandma's house, Juana mastered the guitar", my first guess about someone who said "nuh-uh!" would be that they were challenging the claim about Juana's skill at guitar playing (the at-issue content) rather than her whereabouts last summer (the not-at-issue content). Challenging her whereabouts would likely seem more socially uncooperative and unexpected.

On Stanley's account, propagandistic utterances add problematic not-at-issue content that undermines political ideals. For example, utterances containing code words like "super predator" mark some people (typically young Black and brown men) as monstrous threats, not to be engaged with rationally. This supposedly helped lay the groundwork for the subsequent exclusion of their perspectives or perspectives associated with them in relevant public discussions (e.g. policymakers' conversations about the criminal justice system). This kind of propagandistic effect prevents conversations that include "undermining propaganda" from meeting the Rawlsian political ideal of reasonableness, which requires that all reasonable perspectives be considered in certain political contexts. ${ }^{14}$

This approach requires us to appeal to the propositional content of the speech acts to explain why speech acts undermine democratic ideals - if not in their obvious at issue context, then perhaps in some insidious aspect of their not-at-issue content. But this approach is vulnerable to two objections. First, democratically problematic speech acts may not themselves contain politically problematic content. Instead, they may simply make salient previously established deformities of public information, despite the speech acts themselves

es of other forms of communication (e.g. sign language or text-based communication). This also will include actions that are not typically analyzed as essentially communicative yet that communicate, i.e. waiting in a line, physical violence.

${ }^{14}$ Stanley 2015: 94. 
consisting entirely of innocuous content. ${ }^{15}$ Secondly, this approach assumes that the danger of propaganda is what is public information. But the connection of an incentive structure to the common ground allows us to identify a danger Stanley does not consider: that perverse changes to the incentive structure may alter what public information can be used to do, in ways that can pass through a host of vectors other than belief: namely, all bases for acceptance behavior (fear of embarrassment, coercion, capitulation to social superiors, etc.)

Unencumbered by the ideology-inspired focus on beliefs (roughly equivalent to the common ground's propositional content on an ideology view), a practice first explanation of the common ground and of agenda setting can readily explain why undermining propaganda undermines without succumbing to these objections. Unlike the mechanism of undermining propaganda Stanley focuses on, agenda setting effects can exclude relevant perspectives does not map cleanly onto the at-issue not-at-issue distinction, since both forms of content can work together to produce the agenda setting effect in the first instance. The move from "common belief" to public practical premises isn't just marketing. The content of the common ground is being considered not only for what descriptions of the world it involves (its propositional content) but also which practical uses of that public information are incentivized for or against, who has standing to make which uses of public information, and which uses of public information are likely to be responded to cooperatively. The problematic version of the agenda setting effect I elaborate here will be largely supplementary to Stanley's account, in that it will often help explain why reasonable perspectives are excluded from subsequent discussion in cases of propagandistic speech.

The common ground is not simply a repository of information agreed upon by all participants, but also associated with or itself something like a public schedule of incentives and disincentives on uses of public information. This helps us see a way of changing the common ground that is conceptually separable from adding, subtracting, or altering its propositional content: altering the incentive structure on the uses of public information. I use the term

${ }^{15}$ I term these cases "Trojan horses", and argued for this possibility in "Beware of Schools Bearing Gifts.” Táíwò 2017. 
agenda setting to describe changes to the common ground's associated incentive structure.

\subsection{Agenda setting and conversation}

At-issue content can serve an agenda setting role by proposing a subject of conversation. In the case of a conversation starting with (A) "Juana mastered the guitar last summer", the subject established is one centered on Juana's guitar skills. If we are meant to stay on this subject for some time, this can also affect the interpretive environment for substantive additions to the common ground. If someone next offered a sentence that could not easily be interpreted as responsive to the utterance about Juana, like (B1) "the price of tea in China has increased", it may be perceived as uncooperative and a slight to the previous communicators. Social norms generally incentivize communicators away from doing this.

On the other hand, if someone were to add something more clearly relatable: for example, that (B2) "Rogelio is a guitar master", the effect of the initial statement about Juana still effects its interpretation. This statement (B2) may invite a comparison between the skill levels of Juana and Rogelio in the interpretive environment created by the initial statement about Juana. The very same utterance in a conversation where Juana had not been mentioned may instead have made Rogelio's skill itself the subject of conversation, without any comparative implication.

Not-at-issue content can help further inform the direction of conversation by refining what counts as a licensed contribution to a topic of discussion. This contribution to the agenda setting effect is somewhat subtler than the case of at-issue content but is potentially even more powerful. One way not-at-issue content can direct conversation is by contributing to a conception of what counts as proper contestation of what is at-issue. Take the previous example of a conversation begun with the utterance "Juana mastered the guitar last summer", and suppose that the speaker offers the following warrant for this assertion: (C1) "Juana can play Tosin Abasi solos note for note."

The at-issue content of this additional utterance is a claim about which solos Juana can play note for note, namely, those played by Tosin Abasi. But, if this claim is taken to warrant the previous claim 
about her mastery of the guitar, perhaps more information is added to the common ground. The communicator is taking it for granted that the ability to play the solos of a technical virtuoso like Abasi note for note is an indication that one has mastered the guitar - without some such presumption, it would be hard to see why the communicator bothered to add this information. ${ }^{16}$

Further contextual factors can speak in favor of stronger or weaker interpretations of this warrant: knowing where a conversation takes place, and what has already been said in that conversation may help us guess how the speaker intends for the warrant to relate to the assertion - and, perhaps more importantly, how the audience will understand the warrant to relate to the assertion. For example, on one strong interpretation, the common ground may update to reflect the view that the criterion of technical mastery is the sole or most important proof of mastery. This is one interpretation available on the conversational pathway $\mathrm{A}>\mathrm{B} 2>\mathrm{C} 1 .{ }^{17} \mathrm{On}$ such an interpretation, certain other claims become more socially risky to communicate. In such an interpretive environment, one might find it more socially risky to declare other guitarists masters of their instrument, should their claim to mastery derive from some competing conception of mastery, like expressivity of play or skill at improvisation.

The agenda has been set: it is easier to continue conversation by accepting the principle that underlies the warrant (that technical skill is crucial for mastery) than otherwise. Contributions that conform to this warrant are incentivized, contributions that do not are disincentives. For example: statements like (D1) "Rogelio can play George Benson solos" would be less socially risky in this environment than (D2) "Rogelio can play Eric Clapton solos", if the former guitarist's solos are taken to be more technically challenging than the latter's.

Whether or not communicators will challenge the underlying premise depends not simply on whether they agree with the initial speaker's assessment of what constitutes mastery of the guitar, but,

${ }^{16}$ The thought here is something like the Gricean maxim of relevance. See: Grice, Cole and Morgan 1975.

${ }^{17}$ A conversation with this sequence of communicative acts: "Juana mastered the guitar last summer" > "Rogelio is a guitar master" > "Juana can play Tosin Abasi solos note for note". 
in the event that they disagree, also on precisely what the perceived social risks would be to revealing this disagreement by challenging this assessment as a constituent of the common ground between them, and their tolerance of the aforementioned risks. For ease of exposition I've chosen guitar mastery, a politically innocuous subject, but the insight applies for the same reasons to conversations about or involving ideas about subject matter with higher stakes (i.e. religion, abortion, policing, violence).

Another way not-at-issue content can exhibit agenda setting effects is by contributing to a conception of who is best positioned to contribute on a topic, either in conjunction with or independent of the previous effect I considered. Consider if the speaker had offered this warrant instead of the earlier one about Tosin Abasi solos: (C2) "Blue Note called Juana a 'virtuoso' in their review of her debut album." The communicator here identifies the sort of folks that write for Blue Note (music critics) as people qualified to make the relevant sorts of judgments.

As before, context may further refine how the common ground updates in response to this information. If the utterance is interpreted as positioning music critics as the legitimate arbiters of musical skill, then that position may be added to the common ground as not-at-issue content. As a result, it will become socially risky to offer claims that don't conform to this principle.

For example, take (D3) “My friend Kenyatta thinks Juana's playing is sloppy". Here's one way to describe the stakes of this claim: the conversational pathway A $>\mathrm{B} 2>\mathrm{C} 1>\mathrm{D} 3^{18}$ could lead either to a common ground where content corresponding to the thought that Juana is a skilled guitarist is in the common ground as a public practical premise but also to one where its negation is a public practical premise. If (D3) succeeds, it will be socially easy to take a range of actions, some of them communicative (e.g. making statements that portray Juana as a skilled guitarist) and some not (e.g. hiring Juana as a session guitarist for a recording artist one wants to develop a positive relationship with). (D3) will likely prove an ineffective challenge

\footnotetext{
${ }^{18}$ A conversation with this sequence of communicative acts: "Juana mastered the guitar last summer" > "Rogelio is a guitar master" > "Juana can play Tosin Abasi solos note for note" > "My friend Kenyatta thinks Juana's playing is sloppy".
} 
to the claim about Juana's skills where Kenyatta is not taken to be the aforementioned sort of critic, or where the speaker is the kind of person to lie about what Kenyatta thinks, and effective where Kenyatta is taken to be an authority or exceptionally competent.

When the challenge of (D3) succeeds, it establishes Juana is not a skilled guitarist as public information, perhaps by way of not-at-issue content. ${ }^{19}$ It will be more difficult to perform a range of actions that would be downstream of a contrary public practical premise Juana is a skilled guitarist, the one that might have been grounded had conversation gone differently from point (A). Some of these actions constrained are essentially communicative: one would feel vulnerable to successful challenge if they later try to explain the guitar mastery of some third party by comparison to how Juana plays. But others of the actions constrained by this new feature of the common ground aren't essentially communicative, though they communicate nevertheless: for example, campaigning to hire Juana as an instructor of a guitar masterclass, which may communicate an impression of her level of skill that is incompatible with the common ground that results from a successful (D3) challenge after the pathway (A > B2 > C1 > D3).

If this section was successful, then I've begun to illustrate two conclusions. First, contributions to the common ground change the practical environment for participants in conversation that are related but irreducible to the information conveyed by them. Second, given the preceding paragraph: even contributions to conversation characteristically change the practical environment for their participants in general, and not just their conversational environment.

\subsection{Agenda setting and undermining propaganda}

With this understanding of how the common ground responds to new input, we can revisit Stanley's characterization of undermining propaganda and make out a practice first alternative.

Stanley maintains that undermining propaganda succeeds when people have "beliefs that are resistant to the available evidence" and where those beliefs are flawed in some way that puts democratic

\footnotetext{
${ }^{19}$ It could also simply remove the proposition corresponding to the thought that Juana is a skilled guitarist from the common ground. I won't explore this complication.
} 
ideals in jeopardy. ${ }^{20}$ Contrast this with a practice first reconstruction of Stanley's success conditions: that undermining propaganda succeeds when people act from public practical premises that are resistant to the available evidence, and where those premises direct people towards anti-democratic behavior.

Either Stanley means that undermining propaganda as a political tactic succeeds when these conditions are met, or that propaganda succeeds at undermining democratic ideals when these conditions are met. Both meet with substantial objections from the considerations that motivate a practice first standpoint.

The first interpretive option seems to rely on a mistake about the goals of propaganda as a political tactic. Elites that use undermining propaganda may have the effect of undermining political ideals, but we needn't impute that possibility to them as their goal. If elites are instead trying to protect their social power or accomplish concrete and specific political objectives, they often needn't convince people of the rightness or even plausibility of their position in the way that a debater aims to. It is often possible for elites to cultivate and maintain their social power simply by forcing people to adopt certain beliefs as practical premises for use in public action and public reasoning. This is compatible with even widespread private dissent, in the way that compliments about the emperor's clothes persisted despite the fact that his pronouncements did not change anyone's private beliefs. Genuine persuasion is just one way to accomplish this - intimidation, as is plausibly the case in the story of the naked emperor, is another.

Even supposing the second interpretive option, that Stanley means to be outlining conditions that tell us when a speech act succeeds at undermining a society's democratic ideals, this importantly misidentifies the dangers that undermining propaganda presents for a democratic society. Applying the guiding practice first premise that individuals affect society through their actions, individuals' flawed ideological beliefs are dangerous because they may motivate actions that presume the truth of the flawed world views they contained. We are now in a position to see that the condition where people act in ways that presume the truth of flawed world views is multiply realizable - the content of flawed ideological beliefs may function as

${ }^{20}$ Stanley 2015: 178. 
public practical premises out of cumulative individual acts of deference, self-preservation, or self-promotion.

If Part 2.2. was successful, I have explained how chiming into a conversation - adding content to the common ground - can have agenda setting effects, serving to make some practical responses easy and others difficult. These effects can organize behavior in a social context without changing what many, most, or even any individual people believe. This observation helps show why, when the system mapping mental representations to behavior in social contexts is explained in terms of public practical premises rather than beliefs, ambiguities emerge when attempting to describe changes to it over time. How should we explain, for example, an increase in the political salience of white nationalism to struggles over national immigration policy?

Since the mental representations we are concerned with on the practice first view are public practical premises rather than individuals' beliefs or other psychological states, we don't have to assume that people in general believe anything about immigrants today that they did not yesterday, even if we think recent propagandistic acts are to blame for the changes we are seeing. The propaganda may have changed people's beliefs; alternatively, it may have left people's beliefs unchanged by decreased the social risk aversion of the people who already had white nationalist beliefs, or it may have left their risk profiles intact but changed their perception of the relevant schedule of social costs and benefits to loudly proclaiming and advocating for their beliefs. Each of these would, in the short term, explain what we are observing. A practice first view of things can accommodate any and all of these behaviorally (and thus observationally) similar possibilities.

The alternative "practice first" proposal for characterizing undermining propaganda and its success conditions relies on the proffered distinction between mutual belief and social coordination on public practical premises, the latter of which displaces beliefs (mutual or otherwise) to take center stage in our theories. Consequently, the contrast between a practice first account of undermining propaganda and Stanley's basis of this phenomenon in ideology mirrors the three contrasts between practice first and ideology generally.

First: where Stanley treats undermining propaganda as dangerous because it risks damaging the beliefs and belief-revising processes of individuals in a society, I consider it dangerous because it risks 
altering the representations that guide action, whatever their underlying doxastic implications. ${ }^{21}$ Second: Stanley recommends interventions like "supporting propaganda" that aim to convince or cajole individuals into genuinely improving their moral relationships with each other, thereby heading off the actions that would prevent the realization of democratic ideals in a society. ${ }^{22}$ From a practice first starting point, I can explain both the potential success of that kind of political intervention and also of the much different strategy employed by the residents of Flint to force the government to admit what it already believed to be the case about the quality of its toxic water supply. ${ }^{23}$ Third: Stanley considers the danger of undermining propaganda to consist in what we will presume to know about the world and whether or not we will be willing to revise what we think we know. I consider the danger of undermining propaganda to consist in what putative facts will be treated as knowledge, who will be empowered to wield them, and in what ways. ${ }^{24}$

\subsection{Beyond conversation}

So far tools of philosophy of language have been adequate, since I've focused on their home turf of conversation, following Stanley's focus on speech acts and other communicative acts. But any action in a social context that is publicly perceived may communicate in the sense I'm developing here even if it is not an essentially communicative act. After all, if common ground is simply the store of public information, it follows that the common ground is altered whenever public information is altered.

${ }^{21}$ Stanley 2015: 178. Stanley clearly identifies (individuals') beliefs as his target: "the success of undermining propaganda depends on two things. First, it depends on people having beliefs that are resistant to the available evidence, the evidence that reveals the tension be- tween goal and ideal. Secondly, since undermining propaganda conceals a contradiction of sorts, the beliefs that are resistant to evidence must themselves be awed in some way.”

${ }^{22}$ Stanley 2015: 52-4, 110-2.

${ }^{23}$ Táíwò 2017: 12-4.

${ }^{24}$ Táíwò 2017: 9. I allude to this argument in my discussion of the "social functions of knowledge" on page 9 of this paper. 
This should include many acts in a social context, even ones that aren't conversational. For example: A toddler noisily walking into a room full of adults updates public information about who is in the room, when people notice and take it that others also notice. Since we've characterized the public information in the common ground as public practical premises, we are already ready to consider the effects of actions that change the common ground in practical terms. The toddler walking into the room potentially affects what communicative acts (for instance, ones involving profanity or graphic descriptions) and other acts are incentivized for or against, depending on what the operative norms are about how to relate to children (presumably also in the common ground, if these norms are taken to be understood as such by all parties). ${ }^{25}$ Similarly, a police officer's threatening glare or movement of their hand to their gun holster could have the practical communicative effect that an utterance"stop that or else!" - would have.

Then, it should be possible to sketch a general account of how any public action exerts agenda setting effects on the content and structure of public information. Speech and other overt communication will then be relegated to their proper places: sources of a set of theoretically useful cases that nevertheless make up a mere subset of the overall conceptual space of actions that adjust and restructure public information.

A general formulation of agenda setting, then, can be given exactly the same way as it was in the introduction: agenda setting effects describe changes to the common ground's associated incentive structure. All we need to draw out the implications for actions other than communicative acts is to appreciate the implications of the previous paragraphs in this section.

Consider political violence. Lynne Tirrell describes the waves of disrespectful discourse and slurs that preceded the Rwandan

${ }^{25}$ Bierria 2014; Satz and Ferejohn 1994. In "Missing in Action”, Alisa Bierria goes as far as to define types of agency on the basis of how one is positioned by the relations of dominance in the relevant contexts, a paper which I'm indebted to for many of the insights here. Also, Satz and Ferejohn (1994) argue that rational choice theory, even where it is reliable for making predictions, is compatible with the beliefs of the agents diverging from those the model might be taken to ascribe them. That result is consistent with what I say here. 
genocide as "action-engendering", noting their erosion of the social norms responsible for preventing such violence. ${ }^{26}$ Describing discourse as operating on public practical premises rather than common beliefs helps make out starkly in Stalnakerian terms what Tirrell argues in Jamesian pragmatist terms: since, on a practice first conception of the content of the common ground, the content of the common ground just is about how to act, it's not hard to make out the connection between trends of public practical premises that sanction communicatively relating to members of the Tutsi ethnic group as though they were insects and subsequent exterminatory violence that exploits a public practical premise that Tutsi are to be treated as insects. From an overall social standpoint, murder, imprisonment, and abduction might have effects on public practical premises much like the effects we might attribute to undermining propaganda from a practice first standpoint. As mentioned in 2.3: undermining propaganda succeeds when public information and incentives are adjusted to empower schedules of social behavior that are dangerous for a well-functioning democracy. Either incentivizing anti-democratic behavior or disincentivizing pro-democratic behavior would qualify.

A sustained disinformation campaign from a despotic government - presumably, undermining propaganda if anything is - aims at these same goals. Negatively, the disinformation itself discourages, disempowers, or directly prevents people from publicly resisting an anti-democratic regime. Murder, imprisonment, and abduction of dissidents - the ones themselves killed or disappeared won't have much to say afterwards about resisting the regime, and their terrified surviving comrades might be less bold in the future. Positively, such propaganda might encourage and normalize support of the regime's anti-democratic ends from state lackeys and perhaps even sympathetic vigilantes. Similarly, acts of state violence towards a group of people might communicate the sort of thing that labeling them as "insects" might: that those people are a socially sanctioned target of violence.

The communicative effects of violence at many scales are probably well understood by those who practice it intentionally. At an interpersonal level: Ta-Nehisi Coates has written about the importance

${ }^{26}$ Tirrell 2013. 
of a reputation for personal violence for people that live in violent surroundings. ${ }^{27}$ At a group level: the US military's Iraq War strategy of "shock and awe" was based on the "Rapid Dominance" military theory of the practical communicative effects of large scale violent destruction - namely, its potential "to convey the unmistakable message that unconditional compliance is the only available recourse."28

Chilean economist Orlando Letelier provides a helpful example that both lets us consider violence directed at individuals and also at groups, while relating that violence to the more mundane stuff of politics. Letelier claimed a link between ideological advocacy and state violence, noting CIA involvement with economic planning of the post-coup Chilean government. He hypothesized that there was a direct link between the attempts of foreign public and private financial institutions to institute "economic freedom" and the Pinochet regime's orchestration of "massive repression, hunger, unemployment and the permanence of a brutal police state." ${ }^{29}$ In the terms I'm using in this paper, I think Letelier's observations could be fruitfully re-described as observations about the agenda setting effects that furthered the underlying goals of whatever is signified by "economic freedom", or the perhaps unrelated goals of whomever exerts the most control over how this term structures the common ground.

We would expect that a norm and incentive structure in a neoliberal political environment would make justifications for political action that are articulable as considerations of scarcity, supply and demand, and moral value-neutrality socially prevalent and incentivized for. ${ }^{30}$ Equivalently, it would make claims that are difficult or impossible to

${ }^{27}$ Coates 2011

${ }^{28}$ Ullman et al. 1996: xxvii.

${ }^{29}$ Kornbluh 2013: xiii.

${ }^{30}$ I have a characterization of neoliberalism in mind like Wendy Brown's characterization of the "popular" conception of neoliberalism: "In popular usage, neoliberalism is equated with a radically free market: maximized competition and free trade achieved through economic de-regulation, elimination of tariffs, and a range of monetary and social policies favorable to business and indifferent toward poverty, social deracination, cultural decimation, long term resource depletion and environmental destruction.” Brown 2003. 
articulate in such terms socially scarce and incentivized against. Ideology is well positioned to claim and potentially even explain at least this much. The insight of practice first is this: for the same reasons and by the same mechanisms, such a political environment could incentivize for and against a host of extra-conversational actions.

On the negative side, coercive political acts like the assassinations of Third World political leaders who advocate for political and economic independence from rich countries might have agenda setting effects like the conversational ones considered in 2.2. That is, they may help dissuade elites in the Third World from communicative acts like advocacy of similar policies to the murdered leader, but also non-communicative acts, like the enactment of policy deviating from the priorities of rich nations (e.g. raising tariffs on sectors of the economy rich nations would prefer were open to "free trade"). Such an assassination may help dissuade working class people in the Third World from forming or supporting trade unions. On the positive side, coercive political actions could aid and abet sweeping adjustment of public practical premises in the world that incentivize political elites in the third world to negotiate structural adjustment programs with the first world that "liberalize" their trade policy and subordinate their fiscal targets to the goals of technocrats from the First World.

Other political strategies also have potentially illuminating structural analogues with the phenomena discussed in part II via the more familiar terrain of the spoken conversation. As we've seen, an opening move in a conversation like "Juana mastered the guitar last summer" can set the agenda by setting a topic, thereby making utterances that do not have to do with that topic costlier to offer. Analogously, precarious access to basic material needs could orient the practical life of economically insecure people by making survival the topic of the day - that is, orienting their economic acts around this goal in the way that conversations orient communicative acts around their subject. This state of affairs could remove things like "contact your political representative to protest the new zoning ordinance" from the daily to-do list, in the way that "the price of tea in China" is removed from the conversational to-bring-up list once Juana's guitar playing becomes the thing to talk about.

Similarly, we saw that the utility of an answer like "Kenyatta 
said Juana's playing was sloppy" to a person who believed in Juana's skill depended on the esteem in which Kenyatta is held (and, not for nothing: Kenyatta being around to express this alternative perspective, which would fail if Kenyatta were to be disappeared one day). Dismissing or discrediting activists and intellectuals who would offer an alternative perspective to the elites' preferred one (or putting enough of them in a ditch that those who survive get the message and adjust their practical premises accordingly) could have similar effects on the actions that those affected by the abductions will consider that the invocation of Kenyatta's artistic authority has on the audience of that conversation.

A practice first account of things has the potential to unify our analysis of conversational phenomena like propagandistic speech acts with that of non-conversational phenomena like rent prices, unemployment rates, and terrorism. ${ }^{31}$ This unity can push further inquiry in promising directions. Accounts of ideology which hinge on imputing beliefs to individuals within the targeted political contexts may commit themselves unnecessarily to the risk of serious sociological mistakes about what people's actual epistemic commitments are, what accounts for their behavior, and in turn about what aspects of the political context must be altered to make way for rosier possibilities.

\section{Part III: conclusion}

This paper aimed to lay out a basic sketch of the theoretical commitments of the practice first view and take it out for a spin. Instead of relying on what people actually believe to explain their behavior and derivative political phenomena, this paper relied on what people accept (in Stalnaker's terms), or what they treat as a public practical premise (in my own). A person's acceptance of any given proposition can be explained by the match of the proposition with the individuals' privately held beliefs but also by any number of other factors, such as distraction, the effect of distal or proximate social hierarchies, and forms of epistemic reliance and trust that bypass individuals coming to their own conclusions. Practice first allows one to be agnostic about what explains acceptance. Nevertheless, since

${ }^{31}$ Tirrell 2012. 
the content of the common ground is characterized behaviorally (as public practical premises), conclusions about it can help us explain things individuals and groups do and will do, even where we are unsure what beliefs lie under those actions. ${ }^{32}$ Then, a practical account of propaganda and the dynamics of communication along the lines gestured to in this paper would make much of the same predictions about what people will do, but without the heavy sociological baggage an ideology-based account would likely have.

Other topics on the contemporary literature in social/political philosophy may similarly benefit from opting for a practice first view. The literature on epistemic injustice and related topics seem to operate with ideology-like commitments in the background. Miranda Fricker's Epistemic Injustice characterizes the epistemic injustices it considers (testimonial and hermeneutical injustice) in terms of the stereotype-addled belief states and other mental representations and states (“images") images of the victim's audience. Though Fricker does use a collective understanding of hermeneutic resources to ground her conception of hermeneutical injustice, thus freeing her theory from more flat-footed commitments to the belief-states of the individuals in question, the effect of lacuna in the hermeneutical resources is nevertheless cashed out in terms of which understandings are made available to the collective itself and individuals in it, rather than directly in terms of how the practical space for acting is altered, as I prefer and as a practice-first view would opt for. ${ }^{33}$

Similarly, Charles Mills' article "White Ignorance" characterizes white ignorance as a "social mind-set" marked by false beliefs and the absence of (important) true beliefs that most people use as a basis for thinking about or even perceiving the world, that only a "rare individual" is able to resist. ${ }^{34}$ Then, gaps or imperfections in what is taken to be mutual knowledge, can in this way constrain the field of practical

\footnotetext{
${ }^{32}$ Satz and Ferejohn's argument about rational choice theoretical models is again instructive here.

${ }^{33}$ See $36-8$ for the claims about testimonial injustice and chapter 7 for the claims about hermeneutical injustice, especially pages 147-52. Fricker 2007: 36-8, 147-52.

${ }^{34}$ Mills 2007: 16, 27-8.
} 
options available to any given participant. ${ }^{35}$ The practice first view, here sketched by the pair of agenda setting (given in Part II) and the conception of the common ground that motivates it (given in Part I), poses a challenge to the sort of theories of ideology that Shelby describes generally and that Stanley, Mills, and Fricker instantiate.

The practice first version of things leaves room for the orthodox story that propaganda, epistemic injustice and white ignorance are politically dangerous because they will lead to lots of individuals believing the wrong things and updating their beliefs for the wrong reasons. After all, changing people's private beliefs about what the world is like is one way to influence their action, where those beliefs bear on their decisions about what to do. But the practice first view has two advantages. First, it focuses our attention squarely on what it is that elites get out of any of these kinds of systemic epistemic manipulations, should they succeed at them: undermining propaganda, epistemic injustice, and white ignorance are dangerous because they lead to conformity with the patterns of social action that construct and maintain unjust social relations. This is because of the effect they have on public practical premises, whatever their effect on individuals' mental representations.

Practice first also makes room for a much more capacious understanding of the harmful epistemic consequences of coercion and domination - and, importantly, one that gives the coerced and dominated a little more credit. The implications of coercion and dominance on communication have been discussed in analytic philosophy of language in the analytic tradition as early as David Lewis' "Scorekeeping in a Language Game" in 1976, as well as work in feminist epistemology feminist philosophy of language, and philosophy of race. ${ }^{36}$ Other traditions of philosophical theory and praxis have a long history of engagement with the substance of this topic, in-

${ }^{35}$ Fricker 2007, Woodson 2016, Táíwò 2017. “Gaps in what is taken to be mutual knowledge" corresponds to the lacunae in epistemic resources that Fricker uses to explain how epistemic injustice works. I take Carter G. Woodson to have identified what amounts to a practice first interpretation of what a lacunae in epistemic resources amounts to - a gap in the practical possibilities for the use of epistemic resources. I explain this alternative and some of its implications in Táíwò 2017.

${ }^{36}$ See, for example: Vadas 1987, Langton 1993, Hornsby and Langton 1998, Dotson 2014, Medina 2012, McKinnon —- Táíwò 2017. 
cluding what we might today describe as anarchist and post-colonial traditions, as well as the Black radical tradition. ${ }^{37}$ These traditions make better use out of the multiple possibilities that could explain the efficacy of both propagandistic speech acts and the systems of mental representations that ideology purports to describe.

Crucially, this includes possibilities on which those affected by propaganda and what looks to be "ideology" nevertheless succeed in partially or completely retaining their grip on reality and understanding of their situation.

However, the practice first orientation to social/political theory is not a magic bullet. It is susceptible to a "scaling-up" kind of problem. If successful, I've have identified in part 2.2. how the dynamics of agenda setting in an individual conversation might make sense of political actions described in 2.3. that we would ordinarily view as in the service of ideology or brute coercive power. But this relies on the implicit assumption that there is more than a metaphorical or analogical connection between the dynamics of "political discourse" across a nation, which is an aggregate of very many individual conversations across many groups of people and across years of time, and the dynamics of the individual constituent conversations. This may not be so: the dynamics of public information sharing at the level of a nation may just be too different from the dynamics of in-person conversation.

However, the scale up problem is a problem for any account that purports to explain macro-level social phenomena using explanations generated by an analysis of tools developed for the analysis of micro-level phenomena (conversations between small numbers of people), including ideology based accounts like Stanley's. As such, this problem doesn't provide reasons to prefer previous accounts of social phenomena based on an explicit or implicit theory of ideology — whether Stanley's, Fricker's, or Mills' - to the one I offer here. However, it might provide potential points of intervention for our colleagues in sociology, linguistics, political science, gender studies, cultural studies, and other related fields and help frame future collaborative efforts.

Historians and social scientists may consider testing out a range of historical hypotheses in case the analysis in this paper is useful.

${ }^{37}$ See, for example: Ellison 2016, Bambara 1970, Kelley 1993, Scott 1990. 
It seems possible to define measures of the strength of agenda setting effects, and empirically examine hypotheses about these. These would provide one means to answer research questions about how violent forms of agenda setting like murder, imprisonment, and threats interact with other forms of agenda setting like the construction and maintenance of epistemic hierarchies. It may be that some of the latter may prove the result of the former, or vice versa. ${ }^{38}$

\section{Olúfémi O. Táíwò \\ Department of Philosophy \\ Georgetown University \\ 215 New North Hall}

37th and O Streets, N.W., Washington D.C. 20057

Olufemi.Taiwo@georgetown.edu

\section{References}

Andersen, Hans Christian. 1837. The Complete Fairy Tales and Stories. Anchor, 2011. Bambara, T. C. 1970. The Black Woman: An Anthology. Signet.

Bierria, A. 2014. Missing in action: violence, power, and discerning agency. Hypatia 29 (1): 129-45.

Bright, L. K. and Táíwò, O. 2017. Discourse power. Unpublished Manuscript.

Brown, W. 2003. Neo-liberalism and the end of liberal democracy. Theory and Event 7(1). Project MUSE, doi:10.1353/tae.2003.0020

Coates, T. 2011. The code of the streets. The Atlantic, August 2, 2011. https:// www.theatlantic.com/national/archive/2011/08/the-code-of-thestreets/242963/.

Dotson, K. 2014. Conceptualizing epistemic oppression. Social Epistemology 28(2): $115-38$.

Ellison, R. 2016. Invisible Man. Penguin UK.

Fields, B. J. and Fields, K. 2012. Racecraft: The Soul of Inequality in American Life. Verso Books.

Fricker, M. 2007. Epistemic Injustice: Power and the Ethics of Knowing. New York: Oxford University Press.

Grice, H. P. 1967. Logic and conversation. In Studies in the Way of Words, ed. by Paul Grice. Harvard University Press, 41-58.

Haslanger, S. 2017. Racism, ideology, and social movements. Res Philosophica 94(1): 1-22.

Hornsby, J. and Langton, R. 1998. Free speech and illocution. Legal Theory 4(1):

${ }^{38}$ Thanks to: Dan Zeman, Sahiba Kaur, Lauren Leydon-Hardy, Liam Kofi Bright, Miranda Sklaroff, Daniela Dover. 
$21-37$.

Kelley, R. D. G. 1993. 'We are not what we seem': rethinking black workingclass opposition in the Jim Crow South. The Journal of American History 80(2): $75-112$

Keynes, J. M. 1936. The General Theory of Employment, Interest and Money. London: Macmillan. https://search.library.wisc.edu/catalog/999623618402121.

Kornbluh, P. 2013. The Pinochet File: A Declassified Dossier on Atrocity and Accountability. The New Press.

Langton, R. 1993. Speech acts and unspeakable acts. Philosophy and Public Affairs 22(4): 293-330.

McKinnon, R. 2017. Allies behaving badly: gaslighting as epistemic injustice. In Routledge Handbook to Epistemic Injustice, ed. by Ian James Kidd, José Medina and Gaile Pohlhaus, Jr. London and New York: Routledge, 167-74.

Medina, J. 2012. The Epistemology of Resistance: Gender and Racial Oppression, Epistemic Injustice, and the Social Imagination. Oxford University Press.

Mills, C. W. 2007. White ignorance. In Race and Epistemologies of Ignorance, ed. by Shannon Sullivan and Nancy Tuana. Albany: State University of New York Press.

Potts, C. 2013. Presupposition and implicature. The Handbook of Contemporary Semantic Theory $\left(2^{\text {nd }}\right.$ edition), ed. by Shalom Lappin and Chris Fox. Oxford: Wiley-Blackwell.

Satz, D. and Ferejohn, J. 1994. Rational choice and social theory. The Journal of Philosophy 91(2): 71-87. https://doi.org/10.2307/2940928.

Scott, J. C. 1990. Domination and the Arts of Resistance: Hidden Transcripts. Yale University Press.

Shelby, T. 2003. Ideology, racism, and critical social theory. The Philosophical Forum 34(2): 153-88. https://doi.org/10.1111/1467-9191.00132.

Stalnaker, R. 2002. Common ground. Linguistics and Philosophy 25(5): 701-21.

Stanley, J. 2015. How Propaganda Works. Princeton University Press.

Táíwò, O. O. 2017. Beware of schools bearing gifts: miseducation and Trojan Horse propaganda. Public Affairs Quarterly 31(1): 1-18. http://paq.press. illinois.edu/31/1/01_taiwo.html.

Tirrell, L. 2012. Genocidal Language Games. New York: Oxford University Press.

Tirrell, L. 2013. Studying genocide: a pragmatist approach to actionengendering discourse. In Pragmatism, Law, and Language, edited by Graham Hubbs and Douglas Lind. Routledge.

Ullman, H. K., Wade, J. P., Edney, L. A., Franks, F. M., Horner, C. A., Howe, J. T. and Brendley, K. 1996. Shock and Awe. Achieving Rapid Dominance. National Defense University, Washington DC.

Vadas, M. 1987. A first look at the pornography/civil rights ordinance: could pornography be the subordination of women? The Journal of Philosophy 84(9): 487-511.

Woodson, C. G. 2016. The Mis-Education of the Negro. Middletown: Tribeca Books. 